\title{
THE SOLUTION OF HEATED PUNCH PROBLEMS BY POINT SOURCE METHODS
}

\author{
J. R. BARBER
}

Department of Mechanical Engineering, University of Newcastle upon Tyne, NE1 7RU, England

\begin{abstract}
A method is described for finding the contact pressures and surface displacements of a semiinfinite elastic solid, indented by a rigid, heated punch. The problem is reduced to an equivalent isothermal problem by finding the surface displacements due to temperature changes alone, making use of various properties of the point source solution, and superposing these on the initial profile of the solid. The analysis is greatly simplified if the system is axisymmetric or contains axisymmetric regions. The method is illustrated by an example.
\end{abstract}

\section{INTRODUCTION}

SomE interest has recently been shown in the solution of problems involving the combined heating and loading of solid surfaces. George and Sneddon [1] produced a general theory for solving the problem of a semi-infinite elastic solid, indented by an axisymmetric, heated punch and the method was extended to the axisymmetric, finite solid by Keer and $\mathrm{Fu}$ [2] and to the case of simultaneous indentation by two punches by $\mathrm{Fu}$ [3]. These solutions were derived from the equations of thermoelastic equilibrium by integral transform methods.

In this paper, an alternative method of solution is described which has particular advantages when only the contact stresses and surface displacements are required. The method is discussed in general terms in Part I and its use is illustrated by a particular example in Part II.

\section{Method of solution}

The general problem to be solved is that in which a rigid heated punch of known profile is pressed into the surface of a semi-infinite elastic solid. It is proposed to solve this problem as follows:

(a) The known thermal boundary conditions are applied to the solid in the absence of any contact stresses and the resulting normal displacements at the surfaces are found.

(b) An isothermal solution is then found for the indentation by the rigid punch of a stress free solid with the distorted profile of solution (a).

(c) The required solution for simultaneous heating and loading can then be found by superposition of (a) and (b).

If the thermal boundary conditions are specified in terms of the distribution of heat flux at the solid interface, the solution to problem (a) is most easily obtained by integrating the point heat source solution.

If a steady state, point heat source of strength $q$ is located on the surface of a semiinfinite solid, the normal surface displacement produced at a distance $s$ is

$$
w=\frac{q \alpha(1+\nu)}{2 \pi k} \log \left(s_{0} / s\right)
$$


where $\alpha, k, \nu$ are respectively the coefficient of thermal expansion, thermal conductivity and Poisson's ratio of the material. This result is derived in reference [4]. The distance $s_{0}$ represents an arbitrary reference point at which the displacement is defined to be zero. A finite reference point must be used, since, relative to the finite range, $w$ is unbounded both at the source and at infinity. An essentially similar problem is encountered in two-dimensional, isothermal contact problems and can be avoided by expressing the results in differential form (i.e. in terms of surface slopes). However, in the threedimensional case, the surface slope can only be expressed as a vector quantity and this adds unnecessary complication to the mathematical analysis.

If the heat input per unit area at the surface of the solid is a known function $(q)$ of position, the solution to problem (a) is found by integrating equation (1), i.e.

$$
w=\frac{\alpha(1+\nu)}{2 \pi k} \iint_{A} \log \left(s_{0} / s\right) q \mathrm{~d} A
$$

where $A$ is the region of the surface through which heat flow occurs. If $s_{0}$ is chosen to be large in comparison with the dimensions of $A$, it will be approximately constant and equation (2) becomes

$$
w=\frac{\alpha(1+\nu)}{2 \pi k}\left\{Q \log \left(s_{0}\right)-\iint_{A} q \log (s) \mathrm{d} A\right\}
$$

where

$$
Q=\iint_{A} q \mathrm{~d} A
$$

is the total heat flux into the solid.

If the thermal boundary conditions are not given in terms of the heat input $q$ at the surface, it will generally be necessary to solve the heat conduction equation to find this function before using equation (3) to solve problem (a).

Once the shape of the unloaded, thermally distorted surface is known, the contact pressure distribution (problem (b)) can be found by conventional methods of isothermal contact theory.

A particular solution to equation (3) is worth noting. If a thin uniform annular heat source, radius $a$, is applied to the solid, equation (3) can be evaluated to give:

$$
w=\frac{Q \alpha(1+\nu)}{2 \pi k} \log \left(s_{0} / a\right)
$$

for $s \leqslant a$ and

$$
w=\frac{Q \alpha(1+\nu)}{2 \pi k} \log \left(s_{0} / s\right)
$$

for $s>a$.

Thus, for all points outside the annulus, the normal displacement is equal to that produced by an equal point source at the centre, whereas the normal displacement at all points within the annulus is constant. This result greatly facilitates the solution of problem (a) for systems which are axisymmetric or which have a number of sources which, taken independently, would be axisymmetric. In finding the normal displace- 
ment at any point $P$ on the surface, any axisymmetric source external to $P$ can be replaced by an equivalent point source at its centre and the effect of any axisymmetric sources enclosing $P$ can be found by integrating equation ( $5 a$ ).

\section{Example}

To illustrate the use of the method, we will find the contact pressures and surface displacements due to the indentation of a semi-infinite solid by a flat, rigid cylindrical punch of radius $a$, the heat input being assumed uniform over the contact area and zero elsewhere. i.e.

$$
\begin{array}{rlrl}
q & =q_{0} & 0 \leqslant r \leqslant a \\
& =0 & r & >a .
\end{array}
$$

(Note: This is a particular problem to which a straightforward analytic solution can be obtained and it has been chosen as an example because it illustrates the basic steps of the method without introducing unnecessary mathematical complexity. However, the method is not restricted to problems of this type. For example, a general heat flux distribution $(q)$ could be represented in double series form in equation (3). It is worth noting that the mathematical difficulties inherent in more complex problems tend to occur in the equivalent isothermal problem (b) (in which field there is a wider range of existing solutions) rather than in problem (a)-the evaluation of the function $w$ from equation (3)).

\section{Problem (a)}

The normal displacement due to thermal distortion alone is (from equations $(5 \mathrm{a}, \mathrm{b}$, $6 \mathrm{a}, \mathrm{b}))$

$$
\begin{gathered}
w(s)=\frac{\pi s^{2} q_{0}(1+\nu) \alpha}{2 \pi k} \log \left(s_{0} / s\right)+\frac{q_{0}(1+\nu) \alpha}{2 \pi k} \int_{s}^{a} 2 \pi r \log \left(s_{0} / r\right) \mathrm{d} r \\
=\frac{q_{0}(1+\nu) \alpha a^{2}}{4 k}\left\{2 \log \left(s_{0} / a\right)+\left(1-s^{2} / a^{2}\right)\right\}
\end{gathered}
$$

for $0 \leqslant s \leqslant a$ and;

$$
w(s)=\frac{q_{0}(1+\nu) \alpha a^{2}}{2 k} \log \left(s_{0} / s\right)
$$

for $s>a$, where $w$ is defined as positive away from the solid.

\section{Problem (b)}

The surface defined by equations $(7 \mathrm{a}, \mathrm{b})$ is parabolic in the contact region and hence a contact pressure distribution

$$
\sigma=\frac{q_{0} E \alpha \sqrt{a^{2}-s^{2}}}{\pi(1-\nu) k}+\frac{c}{\sqrt{a^{2}-s^{2}}}
$$

will cause it to conform to the shape of a flat cylindrical punch, where compressive 
stresses are defined as positive, $E$ is Young's modulus for the material and $c$ is an arbitrary constant. (See Timoshenko and Goodier [5] Arts. 124, 125.) This pressure distribution corresponds to a total compressive load

$$
P=\frac{2 q_{0} E \alpha a^{3}}{3(1-\nu) k}+2 \pi a c
$$

Tensile contact stresses are not normally admissable and hence for negative values of $c$ [i.e. $P<2 q_{0} E \alpha a^{3} /(3(1-\nu) k)$ ] the punch will not remain in contact with the solid over its entire area. If $q_{0}$ is negative (i.e. if the punch is cooled), there is no solution without tensile stresses unless $c>-q_{0} E \alpha a^{2} /(\pi(1-\nu) k),\left(P>-4 q_{0} E \alpha a^{3} /(3(1-\right.$ $\nu) k$ )). The conditions holding at light loads are discussed in reference [4].

The normal surface displacement, relative to the point at infinity, produced by the pressure distribution of equation ( 8 ) is

$$
w(s)=-\frac{q_{0} \alpha(1+\nu)}{4 k}\left(2 a^{2}-s^{2}\right)-\frac{\pi c\left(1-\nu^{2}\right)}{E}
$$

for $0 \leqslant s \leqslant a$ and

$$
=-\frac{q_{0} \alpha(1+\nu)}{2 \pi k}\left\{\left(2 a^{2}-s^{2}\right) \sin ^{-1}(a / s)+a \sqrt{s^{2}-a^{2}}\right\}-\frac{2 c\left(1-\nu^{2}\right)}{E} \sin ^{-1}(a / s)
$$

for $s>a$.

The normal surface displacement under combined heating and loading is obtained by superposing the solutions to problems $(a, b)$; thus

$$
w(0)-w(s)=0
$$

for $0 \leqslant s \leqslant a$ and

$$
\begin{aligned}
=\frac{q_{0} \alpha(1+\nu)}{4 k}\left\{2 a^{2} \log (s / a)-a^{2}-\frac{2}{\pi}\left[\left(s^{2}-2 a^{2}\right) \sin ^{-1}(a / s)-a \sqrt{s^{2}-a^{2}}\right]\right\} & \\
& -\frac{c\left(1-\nu^{2}\right)}{E}\left(\pi-2 \sin ^{-1}(a / s)\right)
\end{aligned}
$$

for $s>a$.

The expression (11b) is not bounded as $s \rightarrow \infty$. This result is obtained whenever there is a net steady state heat flow into the solid. If the boundary condition (6b) is replaced by one of zero temperature outside the contact area, an outflow of heat will occur in this region, equal to the heat input in the contact area and the displacement will become finite. This problem is analysed by George and Sneddon [1]. The outflow of heat will be axially symmetrical and, since it surrounds the contact area, it will cause an equal displacement at all points within the latter (see Part I above). Hence the contact pressure distribution for a given applied load $P$ will be unaffected by the change in thermal boundary conditions and is given by equation (8). By a similar argument, equation (8) represents the contact pressure distribution for any arbitrary axisymmetric thermal boundary condition in the region $r>a$. This result is useful, since, in practical 
applications, neither constant temperature nor zero heat flow conditions will occur. However, if the displacement of the punch relative to a distant part of the solid surface is required, the boundary condition must be known and, if this is $q=0, r>a$, a finite displacement will only be obtained by taking account of the finite dimensions of the practical solid (e.g. by referring the displacement to a point near the edge of the surface).

\section{CONCLUSION}

The procedure described above can be used to reduce any heated punch problem to an isothermal contact problem, provided that the boundary conditions at the surface are specified in terms of heat flow or can be converted to this form. The solution is considerably simplified if the system is axisymmetric, or if it contains axisymmetric regions, but the method is not restricted to such cases. In an axisymmetric system, the contact stresses for a given punch load are independent of the thermal boundary conditions outside the contact region and can therefore be deduced from a knowledge of the heat input in the contact region alone. The method may also be used in problems in which the rigid punch is replaced by a second semi-infinite elastic solid with different material properties, the extremities of the two solids being maintained at different temperatures. The case of heat flow between two contacting spheres is considered in reference [4].

\section{REFERENCES}

[1] D. L. GEORGE and I. N. SNEDDON, J. Math. Mech. 11, 665 (1962).

[2] L. M. KEER and W. S. FU, Int. J. Engng Sci. 5, 555 (1967).

[3] W. S. FU, Int.J. Engng Sci. 8, 337 (1970).

[4] J. R. BARBER, Int. J. Heat Mass Transfer, 14, 751 (1971).

[5] S. P. TIMOSHENKO and J. N. GOODIER, Theory of Elasticity, 2nd Edn. McGraw-Hill (1951).

(Received 23 December 1970)

Résumé - Une méthode est décrite pour trouver les pressions de contact et les déplacements superficiels d'un solide élastique semi-infini, marqué par un poinçon chauffé rigide. Le problème est réduit à un problème isothermique équivalent en trouvant quels sont les déplacements superficiels dus aux variations de température seulement, en utilisant diverses propriétés de la solution de source ponctuelle, et en superposant ceux-ci au profil initial du solide. L'analyse est grandement simplifiée si le système est à symétrie axiale ou contient des domaines à symétrie axiale. La méthode est illustrée par un exemple.

Zusammenfassung-Eine Methode zur Ermittlung der Berührungsdrucke und Oberflächenverlagerungen eines einseitig-unendlichen elastischen Festkörpers, der von einem starren, erhitzten Stempel eingedrückt ist, wird beschrieben. Das Problem wird auf ein gleichwertiges isothermes Problem durch Ermittlung der Oberflächenverlagerungen, die nur auf Temperaturänderungen zurückzuführen sind, reduziert, wobei verschiedene Eigenschaften der Punktquellenlösung verwertet werden, und Überlagerung dieser auf das Anfangsprofil des Festkörpers. Die Analyse wird sehr vereinfacht wenn das System achsensymmetrisch ist oder achsensymmetrische Bereiche enthält. Die Methode wird durch ein Beispiel erläutert.

Sommario-Si descrive un metodo per scoprire le pressioni di contatto e gli spostamenti superficiali di un solido elastico seminfinito, intaccato da un punzone rigido e riscaldato. Il problema viene ridotto a uno isotermico equivalente scoprendo gli spostamenti superficial causati dai soli cambiamenti de temperatura e facendo uso di varie proprietà della soluzione della sorgente di punto e sovrapponendole sul profilo iniziale del solido. L'analisi è grandemente semplificata se il sistema è assisimmetrico oppure contiene regioni assisimmetriche. Il metodo è illustrato con un esempio. 
Абстракт - Описан метод для нахождения контактных давлений и поверхностных смешений полубесконечного, упругого, твердого тела, вдавленного жестким подгретым пуансоном. Проблема сводится к эквивалентной изотермической проблеме нахождением поверхностных смешений, обусловенных только температурными изменениями, используя некоторые свойства решения для точечного источника, наложенные на началный профиль твердого тела. Анализ упрощается значительно в случае осесимметрической системы, или если система содержит осесимметрические зоны. Дан пример применения метода. 